\title{
Der terministische Streit
}

Vorgeschichte, Verlauf und Bedeutung eines theologischen Konflikts an der Wende vom 17. zum 18. Jahrhundert

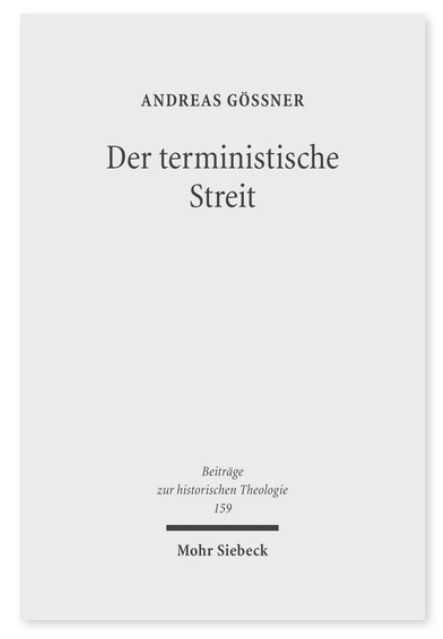

2011. XIII, 495 Seiten. BHTh 159

ISBN 978-3-16-151069-4

DOI 10.1628/978-3-16-151069-4

eBook PDF $174,00 €$

ISBN 978-3-16-150851-6

Leinen $174,00 €$
Der terministische Streit ist eine für die Formierungsdebatte zwischen lutherischer Orthodoxie und Pietismus zentrale theologische Kontroverse. Diese mit einem enormen publizistischen Aufwand und unerbittlicher Schärfe ausgetragene Auseinandersetzung drehte sich um die Frage nach der Befristung der Gnadenzusage Gottes (»terminus peremptorius«). Andreas Gößner rekonstruiert die Debatte in ihrem Verlauf, in ihren personalen, publizistischen, universitäts- und territorialgeschichtlichen Dimensionen umfassend und ordnet sie in ihrer theologiegeschichtlichen Bedeutung ein. Sie betraf nicht nur eine zentrale theologische Problemstellung, sondern reichte weit in den Bereich seelsorgerlicher Praxis hinein. Am Beispiel des terministischen Streits analysiert der Autor so die grundsätzliche Normierungs- und Steuerungskrise des protestantischen Kirchentums und seiner Institutionen am Übergang vom 17. zum 18. Jahrhundert.

Andreas Gößner Geboren 1967; Studium der evangelischen Theologie in München; 1997 Promotion zum Dr. theol.; 2002 Promotion zum Dr. phil.; 2009/10 Habilitation; z.Zt. Lehrkraft für Kirchengeschichte und Didaktik der Kirchengeschichte an der Universität Kassel; zugleich Privatdozent an der Georg-August-Universität Göttingen.

Jetzt bestellen:

https://mohrsiebeck.com/buch/der-terministische-streit-9783161510694?no_cache=1

order@mohrsiebeck.com

Telefon: +49 (0)7071-923-17

Telefax: +49(0)7071-51104 